\title{
Gamificação da Matemática no Instituto Federal do Amazonas
}

\author{
Gabriel Pinheiro Compto ${ }^{1}$, Francisco Lucas Lima Sena ${ }^{2}$ \\ ${ }^{1}$ Instituto Federal do Amazonas (IFAM) - Campus Tefé \\ ${ }^{2}$ Universidade Federal do Amazonas (UFAM) \\ gabriel.comptodifam.edu.br, flls2307@gmail.com
}

\begin{abstract}
This article aims to highlight the importance of the development of digital games for the teaching and learning process of Mathematics. Digital games were developed using gamification concepts and the Unity $3 D$ engine. Four Mathematics-themed games were developed by IFAM students - Tefé Campus, 3rd series, which brought new opportunities for an area that is growing.
\end{abstract}

Resumo. Este artigo tem por objetivo destacar a importância do desenvolvimento de jogos digitais para o processo de ensino e aprendizagem da Matemática. Os jogos digitais foram desenvolvidos utilizando conceitos de gamificação e a engine Unity 3D. Quatro jogos com temática educacional da Matemática foram desenvolvidos por alunos da $3^{a}$ série de Informática do IFAM - Campus Tefé, o que trouxe novas oportunidades para uma área que encontra-se em crescimento.

\section{Introdução}

Desde o primórdio da sociedade vemos que os jogos foram utilizados, pois nela se encontram características lúdicas como: ordem, tensão, movimento, mudança, ritmo e entusiasmo; fazendo com que os mais jovens aprendessem valores morais, normas e conhecimentos; nos quais são pontos característicos na formação de uma cultura, e os jogos, por intermédio do seu potencial lúdico, desenvolveu um papel educacional na vida de muitas pessoas. (HUIZINGA, 2000).

Apesar de muito produtivo, existe uma carência muito grande desses recursos no meio educacional. Almeida (2003) considera a Educação como o ato da troca, de interação e apropriação, algo que vemos nos jogos. A metodologia de ensino que utiliza jogos não vem para discriminar o método tradicional de ensino, já que este também é produtivo em diversos sentidos, mas mostrar que os jogos podem ser inseridos no meio educacional, ou seja, abrir as portas para a possibilidade do uso de novas ferramentas, dentro e fora do ambiente escolar. Tal conceito é denominado Gamificação (do inglês gamification), onde são utilizadas técnicas de jogos, como: mecânica, estatística e dinâmica; aplicadas ao processo de ensino-aprendizagem de determinado assunto considerado complexo. (BORGES et al., 2013)

Não há como não citar o campo de maior dificuldade de aprendizado dos alunos: a Matemática. Nos últimos anos, é notável que muitos jovens tenham tido dificuldades para desenvolver suas habilidades em exatas; em todos os lugares podemos encontrar 
VIII Congresso Brasileiro de Informática na Educação (CBIE 2019)

Anais do XXV Workshop de Informática na Escola (WIE 2019)

pessoas que sempre encontram barreiras para gostar desse campo, dito como o mais complexo. A pontuação média dos jovens brasileiros de 15 anos na avaliação de Matemática do PISA 2015 foi de 377 pontos, valor significativamente inferior à média dos estudantes dos países membros da OCDE que é de 490 pontos (BRASIL, 2016). Isso mostra que a Matemática utilizada na escola não é o suficiente para fixar o conteúdo no cotidiano do estudante brasileiro e apresentar a importância da disciplina na vida das pessoas. No Brasil, essa falta de interligação da Matemática com a vida cotidiana é um grande problema para a educação, pois a Matemática é a ciência que está em tudo: no supermercado, na escola, no trabalho, nos jogos, no cotidiano do ser humano.

\begin{abstract}
No contexto do ensino da matemática, a aprendizagem depende de ações que caracterizem experimentação, interpretação, visualização, indução, abstração, generalização e demonstração, as quais podem ser realizadas através da interação dos alunos com Tecnologias de Informação e Comunicação (TICs), como os jogos digitais e os objetos de aprendizagem, considerados poderosas ferramentas de apoio aos processos de ensino-aprendizagem. (SILVA \& COSTA, p. 21, 2017)
\end{abstract}

Assim, procuramos ferramentas que ajudem no desenvolvimento de jogos digitais, estimulando os alunos do IFAM - Campus Tefé a criarem jogos no campo da Matemática, expondo estes à população tefeense, demonstrando que o aluno, enquanto joga, tende a desenvolver habilidades como obedecer e cumprir determinadas regras.

\title{
2. Materiais e Métodos
}

A metodologia adotada foi a pesquisa exploratória, seguindo três etapas: $1^{\mathrm{a}}$ Etapa Revisão bibliográfica; 2a Etapa - Desenvolvimento de jogos; e $3^{\mathrm{a}}$ Etapa - Mostra dos jogos. Na primeira etapa, foram levantas pesquisas bibliográficas sobre Gamificação e ferramentas que facilitem o desenvolvimento de jogos. Na segunda etapa foi realizada uma oficina de desenvolvimentos de jogos digitais. Por fim, na terceira etapa, os jogos digitais, desenvolvidos na oficina de desenvolvimento de jogos, foram apresentados à comunidade.

\subsection{Game Engine Unity 3D}

Em busca de ferramentas que facilitem o desenvolvimento de jogos para diversas plataformas, encontramos as games engines ou motores de jogos, que são um conjunto de bibliotecas ou softwares que permitem e facilitam o desenvolvimento de jogos, em particular escolhemos a game engine Unity 3D. A engine Unity 3D permite que o desenvolvedor possa escolher programar entre as linguagens de programação JavaScript ou C\#.

Para maior facilidade, resolvemos utilizar a linguagem de programação orientada a objetos C\#, tal linguagem de programação é fácil de aprender por programadores que já trabalharam com as linguagens de programação $\mathrm{C}, \mathrm{C}++$ ou Java. $\mathrm{O}$ uso da linguagem de programação C\# não causou tanto impacto na adaptação dos alunos, pois os alunos do Curso Técnico de Nível Médio Integrado em Informática do IFAM - Campus Tefé possuem na sua matriz curricular disciplinas que possuem o ensino de linguagens de programação C, C++ e Java. 
VIII Congresso Brasileiro de Informática na Educação (CBIE 2019)

Anais do XXV Workshop de Informática na Escola (WIE 2019)

\subsection{Oficina de Desenvolvimento de Jogos Digitais}

Foi realizada uma Oficina de Desenvolvimento de Jogos Digitais com 20 (vinte) alunos da turma da $3^{\text {a }}$ série do Ensino Médio Integrado em Informática do IFAM Campus Tefé, todos estes voluntários, onde foram apresentados os conceitos necessários para o desenvolvimento de jogos digitais com a engine Unity 3D. Na oficina foram desenvolvidos jogos por equipes, com a finalidade de facilitar a aprendizagem da Matemática. A oficina de desenvolvimento de jogos digitais, também, foi realizada com a finalidade de extrair dos alunos o pensamento Matemática e aplicá-lo em jogos digitais através da Gamificação.

\section{Resultados e Discussões}

Como resultado deste trabalho, foram obtidos quatro jogos educativos produzidos pelos alunos formandos da $3^{\mathrm{a}}$ série de Informática do IFAM - Campus Tefé. Todos os jogos tiveram uma finalidade em comum: mostrar a Matemática de maneira lúdica e divertida.

\subsection{Matemática nos jogos: Math Man}

O jogo teve como referência o renomado e reconhecido jogo MARIO WORLD $^{\mathrm{TM}}$. Neste jogo 2D, o jogador deverá alcançar uma pontuação fixa de 80 (oitenta) pontos em três fases distintas. Para alcançar este objetivo o jogador deverá somar os resultados das operações algébricas que são geradas aleatoriamente como uma "chuva de operações", conforme pode ser observado na Figura 1. Também são gerados os números primos, representados pelas bolinhas pretas, com elas o personagem perde 05 pontos de sua pontuação. Este jogo possui como objetivo facilitar, de forma lúdica, o processo de aprendizagem das operações básicas da Matemática, como: soma, subtração, multiplicação e divisão.

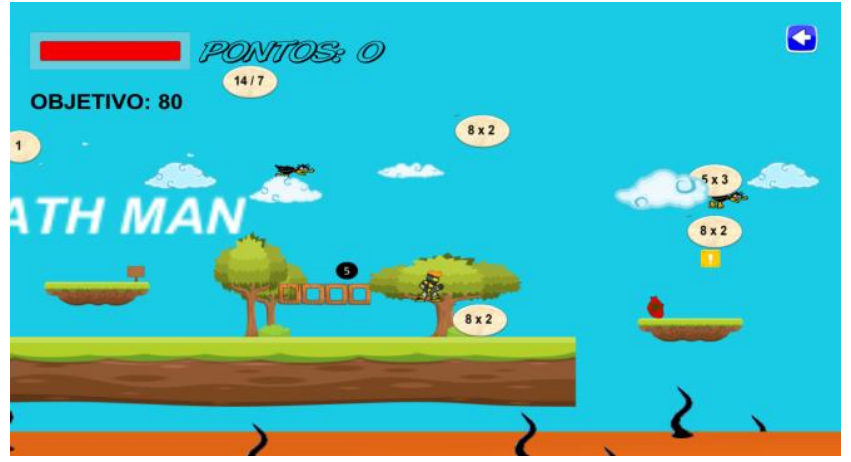

Figura 1. Jogo Math Man.

\subsection{PAC MAT}

Este jogo foi baseado no jogo clássico denominado PAC-MANTM. O jogo é dividido em três níveis sequenciais, sendo: $1^{\circ}$ nível - números primos; $2^{\circ}$ nível números pares; e $3^{\circ}$ nível - números ímpares. Se o número que o jogador pegar for correspondente ao objetivo, esse número se transforma em pontos positivos, caso contrário pontos negativos. No jogo também há quatro frutas, cada uma com um sinal de operação Matemática, como o sinal de soma que acrescenta a pontuação cada vez que ele pega um número, a subtração que decrementa um a pontuação cada vez que ele pega 
VIII Congresso Brasileiro de Informática na Educação (CBIE 2019)

Anais do XXV Workshop de Informática na Escola (WIE 2019)

um número, a divisão que reduz sua velocidade pela metade e a multiplicação que duplica sua velocidade. O objetivo deste jogo é facilitar o processo de aprendizagem de conceitos como: números primos, números pares, números ímpares e operações Matemáticas. Na Figura 2 pode ser observada a tela do jogo PAC MAT.

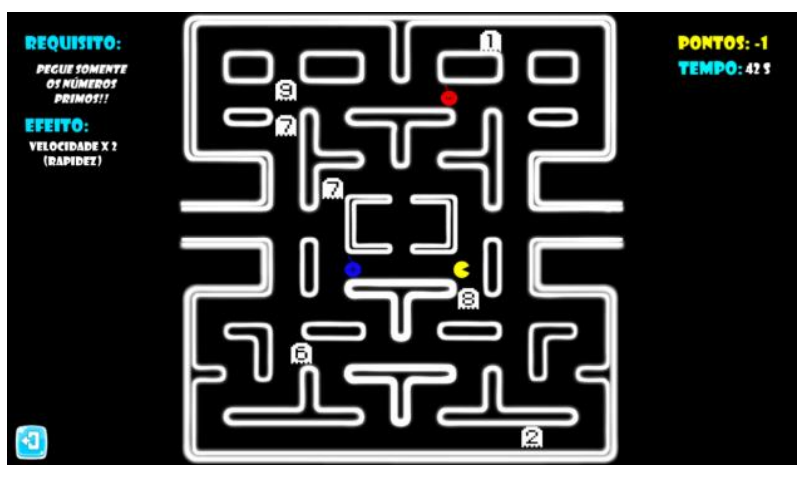

Figura 2. Jogo PAC MAT.

\subsection{Mat Color}

Mat Color é um jogo 2D, onde seu objetivo é pegar as bolinhas de diferentes cores, são quatro bolinhas diferentes, vermelha equivale -1 ponto, a verde +2 pontos, a amarela +1 ponto, e a bolinha cintilante muda o sinal das bolinhas por um tempo determinado. O jogador deverá alcançar a meta que varia de 65 a 75 pontos, ou seja, o jogador deverá usar bolinhas diferentes para alcançar a pontuação exata, sem ultrapassar. O objetivo deste jogo é facilitar o processo de aprendizagem das operações Matemáticas. Na Figura 3 pode ser observada a tela do jogo Mat Color.

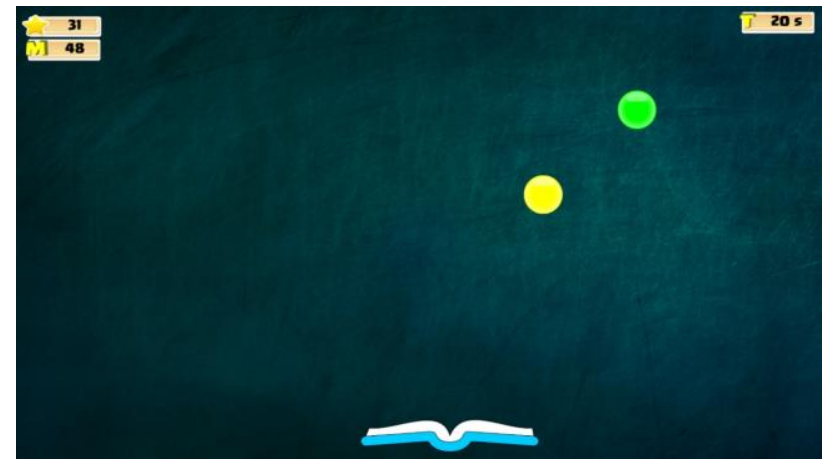

Figura 3. Jogo Mat Color.

\subsection{Gamificação da Matemática: Caminho da Matemática}

Este jogo apresenta um cenário escolar, com o fundo de um quadro negro, onde o jogador deverá resolver uma expressão Matemática simples, em seguida, deverá verificar qual das três opções apresentadas é a correta. Com isso o jogador deverá trilhar o caminho de uma bolinha retirando os pregos de estantes penduradas no quadro, trabalhando não só as expressões Matemáticas, como também a coordenação motora e velocidade de raciocínio lógica. O Jogo é subdivido em dez fases, em cada fase o jogador terá 60 segundos para resolver o problema. Na Figura 4 pode ser observada a tela do jogo Caminho da Matemática. 
VIII Congresso Brasileiro de Informática na Educação (CBIE 2019)

Anais do XXV Workshop de Informática na Escola (WIE 2019)

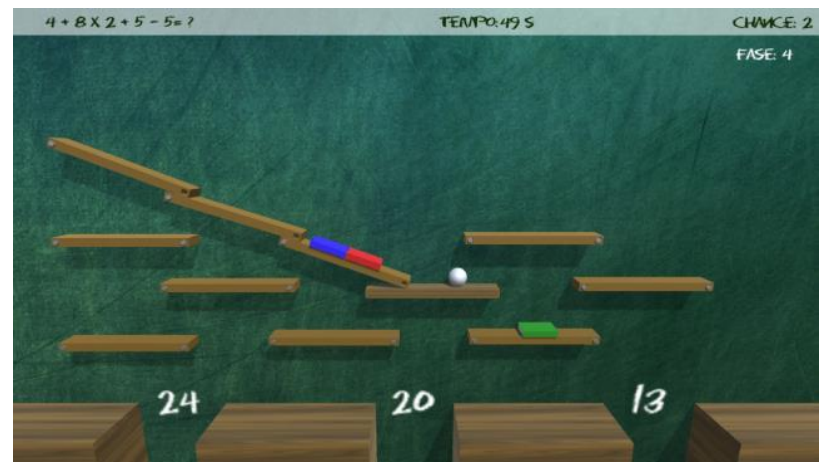

Figura 4. Jogo Caminho da Matemática.

\section{Conclusão}

No ápice da pesquisa, conseguiu-se disseminar o conhecimento adquirido através da Oficina de Desenvolvimento de Jogos, onde os alunos voluntários da $3^{\mathrm{a}}$ série do Ensino Médio Integrado em Informática do IFAM - Campus Tefé desenvolveram quatro jogos para ensinar conceitos da Matemática. Os jogos foram apresentados à comunidade tefeense na Semana Nacional de Ciência e Tecnologia do Campus, conforme pode ser observado na Figura 5. A apresentação dos jogos foi um momento para explicar os mecanismos dos jogos e os conceitos da Matemática que estão neles.

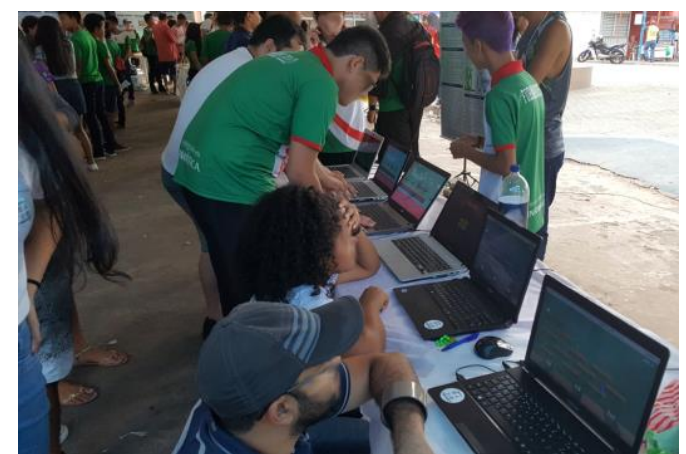

Figura 5. Exposição dos jogos para a comunidade.

\section{Referências}

Almeida, P. N. (2003). Técnicas e Jogos Pedagógicos. 6. Ed. Rio de Janeiro: Loyola.

Borges, S.S.; Reis, H.M.; Durelli, V.H.S.; Bittencourt, I.I.; Jaques, P.A.; Isotani, S. (2013). Gamificação Aplicada à Educação: Um Mapeamento Sistemático. In: XXIV Simpósio Brasileiro de Informática na Educação. Porto Alegre: SBC.

Brasil. Instituto Nacional de Estudos e Pesquisas Educacionais Anísio Teixeira (INEP). (2016). Brasil no Pisa 2015: Análises e reflexões sobre o desempenho dos estudantes brasileiros. Brasília: Fundação Santillana, 2016.

Huizinga, J. (2000). Homo Ludens: vom Unprung der Kultur im Spiel. 4. Edi. São Paulo: PERSPECTIVA S.A.

Silva, K. C.; Costa, M. N. D. (2017). Jogos Digitas na Escola: a utilização como objetos de aprendizagem no ensino da matemática. In: CBIE 2017 - XXIII Workshop de Informática na Escola, 2017, Recife. 